\title{
VALUE-ADDING ACTIVITIES LEVEL IN BRAZILIAN INFRASTRUCTURE CONSTRUCTION COMPANIES - 9 CASES STUDY
}

\author{
Bernardo Martim Beck da Silva Etges ${ }^{1}$
}

\begin{abstract}
This paper presents an approach to answer the question of what is the level of valueadding activities that infrastructure projects usually operates. Considering the Lean Construction concepts, waste definitions and Value Stream Mapping, added to an Operational Excellence perspective, the paper bring the result of nine infrastructure projects conducted by a consultancy company in seven Brazilian Construction Companies. In the presented analysis, eight projects took place in Brazil and one in Trinidad and Tobago.

The methodological analysis here presented consists of two standard phases of the referred consultancy projects where on-site and data analysis, construction value stream mapping, and "gemba-walk" are used to understand the project and quantify the level of value-adding activities and wastes in the construction process. The Multi Moment Analysis will be used to measure wastes and value added in operations performed on-site.

The results show a low level of value-adding activities, representing, in the general analysis, $26 \%$ percent of the total available time. The results are also divided for project and type of operation, i.e. earthworks, steel assembly, pre-fab, for example. That analysis brings the possibility to understand specifics characteristics of each project product and different approaches towards planning and production control and a new managing attitude in each company. This understanding was hold in those construction companies and may be a great improvement opportunity for the infrastructure construction sector.
\end{abstract}

\section{KEYWORDS}

Value-adding activities, Gemba, Value stream map, Multi Moment Analysis

\section{INTRODUCTION}

Lean construction, from concept definition, seeks to increase productivity in construction industry (Issa, 2013). The goal is to understand the production as a sum of flow and transformations activities that deliveries value to the customer (Koskela, 1992, Koskela,

1 M.Sc. Eng, Project Manager, Steinbock Consulting, Etges Engenharia, Climb Consulting, Porto Alegre, Brazil; bernardo.m.etges@gmail.com 
2000). In this perspective, improving practices of construction processes, seek to understand and maximize the activities that add value on the product. For achieving increased levels of activities that add value is essential understand the production operations and how to identify inefficiencies in the process (Rother and Shook, 1998).

Given the premise of understanding the operational level of value-adding activities as a basis or kaizen implementations and productivity improvement, construction groups, focused on infrastructure in the public and private sector in Brazil are investing in improvement consulting processes and implementation of operational excellence programs. To understand the level of value-adding activities on site, the process diagnostic step is conducted integrated three main concepts: Waste identification, Value Stream Mapping and Gemba routines and observations of the shop floor. In this last, the Multi Moment Analysis (MMA) will be used to enable quantify value-adding activities and wastes. The lack of literature about the using MMA on construction is a limitation but also a factor that motivates this study.

The goal of this initial diagnostic step, which precedes the productivity improvement implementations, is to understand the processes involved in operational or support activities to provide resources and sufficient information for production. Thus, this study aims to illustrate the value-adding status in infrastructure projects in the public and private sector. It also aims to demonstrate the use of production analysis tools that allow us to understand the zero line for the implementation of productivity kaizens the analysed works.

The results presented were developed in projects in partnership between those Brazilian Construction Companies and a Consulting Company in nine infrastructure projects in the public and private sector held in Brazil and Trinidad and Tobago between 2013 and 2017. All the projects were performed by Brazilian construction companies. This analysis considered the Value Stream Mapping and wastes observation through Gemba Walk.

The following paper is divided in three phases. First will be explored the conceptual references in the literature about adding value, wastes, value chain and value stream mapping, and how to identify value throw the understanding the production process. Second, the paper will describe the methodology used to identify value-adding activities in the production process, and, in the end, will be presented the results and discussions from analysis.

\section{BACKGROUND}

This section will bring the literature review of four main concepts and tools used to understand the value-adding activities in the construction processes. Those are: (a) value adding activities and waste definitions; (b) Value Stream Mapping; (c) Gemba Walk and (d) Multi Moment Analysis.

\section{VALUE-ADDING ACTIVITIES AND WASTES}

The traditional definition for value-adding activities was made by Koskela (1992) and states: "Value-adding activity: Activity that transforms material and/or information 
towards that which is required by the customer; Non-value-adding activity (also called waste): Activity that takes time, resources or space but does not add value".

Non-value-adding activities is connected to production wastes. The seven wastes were identified by Taiichi Ohno in 1988. These included: overproduction; time on hand; transportation; processing itself; stock on hand; movement; and making defective products. Ohno argues that the elimination of these seven wastes will reduce the nonvalue activities level (Ohno 1988).

Koskela (1992), also argued that non-value-adding activities have three root causes: design, ignorance and the inherent nature of production. The previously definition is aligned with the discussion proposed by Koskela et al, (2013) where "classical list of seven wastes indeed its context specific and that for the context of construction, the crucial wastes have to be identified and defined starting from the characteristics of this type of production". Ins this scene, to analyse the possibility of wastes in a construction site, three major requirements must be considered: the list of wastes should "be conceptually compatible with construction project, empirically justified (i.e. focusing on the most significant wastes) and persuasive and motivating for action of improvement." (Koskela, et al., 2013). For this reason, the Value Stream Map is a key step for waste understanding in each project, considering the seven wastes as one possible reference.

\section{VALUE STREAM MAPPING}

Rother and Shook (1998) defined the Value Stream Mapping (VSM) as a process improvement technique that has the objective to maximize value for the final customer. This value-adding to customers consists of an analysis of identifying and eliminating waste in the entire value chain (Rother and Shook, 1998). VSM has been used and had shown good results providing significant improvements in efficiency, productivity and service quality, and to bring a reduction in production lead and production work process (Shou, et al., 2016).

In construction, VSM was previously used on the analysis of Supply Chain and flow of resources from the supplier to the construction site. (Dos Reis and Picchi 2003; Fontanini et al., 2008 and Picchi 2003). Recently, new studies considered the analysis on production on site itself (Bulhões et al. 2011; Fontanini et al. 2008; Pasqualini and Zawislak 2005). Covarrubias et al. (2016) used VSM, for improving administrative processes in construction. A recent study, developed by Shou, et al. (2016) had analysed the critical success factors on VSM for the construction perspective and identified, through a literature review, that the construction sector has recognized the functionalities of VSM, and used it as an effective lean tool to improve process performance. However, construction did not use the full capability of VSM because of the negative effect of variations in construction projects (Shou, et al., 2016).

Another benefit on VSM implementation in Lean projects isits capability toillustrate, in a systemic way, a stage or level of the productive process of construction, and, also identify possible problems and wastes. Pasqualini and Zawislak (2005) concluded that if VSM is truly applied, in the sense that it considers the productive activities, the customers and the suppliers of the process, following the value flow, the VSM can show more than wastes identification, but also the reasons the wastes exist in the value chain. 


\section{GEMBA WALK}

Ohno (1988) described as a practice of Toyota Production System, the routine of going and seeing how the work happens at the shop floor. The simple act of observing production tasks as they happen could bring insights to understand production. Shook (2009), in his analysis about NUMMI factory, concluded that behaviour is a key factor for improvement. For people change their mind about their own assumption the only way is by changing their behaviours. It just happened when managers started to see and understand the problems of production and themselves (Shook, 2009).

The Japanese word Gemba means the real place, and lean practitioners use it to refer to the place where value is created in production (Kerem, et al 2013). Gemba walks is used to represent the walks managers do to see production tasks where they happen. Managers who are familiar with Lean concepts often call their team members to go to the Gemba and see work practices themselves (Samudio et al, 2011).

In construction the use of Gemba is not common. Two previously papers were published considering this approach (Samudio et al. 2011; Kerem et al. 2013) and one poster (Deschamps et al. 2015). However, this lack of information on literature, both papers brought interesting results. Samudio et al. (2011) concluded that the metrics collected by the project team indicate that the team's efforts have in fact improved their performance and the implementation of improvement. Kerem et al. (2013) brought an important insight considering that the managers discovered that none of the wastes they observed, had never been reported to management and would have remained unidentified if not for the Gemba session. After the Gemba, several managers said that even though they had heard and learned about lean in the past, they had never been able to link it to their daily work (Kerem et al. 2013).

\section{MULTI MOMENT ANALYSIS}

Plange (2015), defines a Multi Moment as a special statistical technique that enables you to gain data and information about your project and work procedures. Its main objective is to provide data and MMA enable to distinguish value-adding tasks and activities from wastes (Plange, 2015).

Even if we identify a lack of the application of MMA on construction industry, in this paper the methodology of data collecting consists in making use of this tool and applying the MMA in observing a shop floor and at regular periods, taking a photograph of the activities under execution. With every picture, the number of employees that are in production or developing activities that add value to the product are counted, employees who are in support activities such as transport, displacement, quality inspection (Nonvalue-adding activities - but needed), and employees at the time of photograph, are totally idle in waiting, delays, hand excess work or rework activities. The latter portion of employees are those in Non-value activities - waste. The MMA were made considering periods of at least 30 minutes of activity, and in some cases, whole shifts at which the input mobilization and demobilization output of the forward service were considered. 


\section{METHODOLOGY}

The analysis and results presented in this paper were developed by a Consulting Company in partnership with another Brazilian Construction Companies in nine infrastructure projects in the public sector and private held in Brazil and Trinidad and Tobago between 2013 and 2017.Main aspects of the projects are presented:

- Intracity works characterized by preferential bus lanes (Intracity A and Intracity B) that were held in the same period in the same Brazilian city (what means the same interface with population and city traffic operation), with similar design and construction methodology, but performed by different construction companies.

- Highway A and Highway B, one covering the construction of new Highway with $52 \mathrm{~km}$ (Highway B) and more than 30 bridges and concrete drainage structures; and Highway A is characterized by improvements in an existing Highway. In Highway A, the longest paving path was around $3.5 \mathrm{~km}$.

- Railway covering one of the largest Railway investment in Brazil in the last decade. The project holds earthworks, bridges, stations and viaducts in more than $235 \mathrm{~km}$.

- Pipeline A and Pipeline B were projects for the Oil and Gas Industry. Pipeline A consisted of a 7-pipe lane between two Oil Mills with 48km long. Pipeline B is a Central Pipeline in one of those Oil Mills. Those two projects are characterized by contract modality of Engineering-Procurement-Constriction (EPC).

- Building Project are those that are involved with edification constructions. Building A was an affordable housing project and Building B was a big educational investment in constructing more than 40 public schools in one of the Brazilian main cities.

The data collection took place during the Consultancy support period and comprises two phases of the Workshops: (a) Analysis/Diagnosis and (b) Kaizen Workshop.

- Analysis/Diagnosis: In this phase is mapped the VSM for the main activity and the Gemba and waste analysis is conduced: the 7 wastes defined by Ohno (1988) are used as references. In order to identify wastes and their impacts, the following tools are used: (a) Gemba-Walk, which consists of observing and finding evidence of the aforementioned wastes; (b) Multi Moment Analysis (MMA), a count of people who add value or for some of the types of the seven wastes, an analysis of several consecutive intervals of time; (c) Chrono-analysis, which consists of an unbroken period of filming over a long period (minimum of 4 hours) to observe the level of value-adding in complete cycles of activities. Because of the low level of Chrono-analysis, the data collected with this tool will not be considered in the results of this paper.

- Kaizen Workshop: 7-phase Workshop, where in the third step the project team go deeper in the VSM analyses and after the process has been mapped and the value stream has been clarified, the Workshop team engages on field-work in order to 
identify and quantify failures and wastes. The team is split up to cover some formats of analysis that include: Identifying the seven wastes; a spaghetti diagram; a MMA for periods of at least 30 minutes of observation.

As mentioned in the previously section, the wastes analysis must be conceptually compatible with the construction project (Koskela et al., 2013). For that, during the VSM the workshop team was conducted to describe the most predicted and expected waste. To quantify wastes and the level of value-adding activities the MMAis the most used tool.

\section{RESULTS}

In all the nine construction projects focused in this paper were had the Diagnosis phase; in seven of those projects were developed the Kaizen Workshop too. In these cases, the data collected in both workshops were analysed.

In both phases of the consultancy project (Diagnosis and Kaizen Workshop) the value stream was identified as the kick point of observation in Gemba. Most of them were activities that in the projects critical path. Nevertheless, in some cases the observed activities considered construction phase that the company did not domain the constructive process. For example, in one of the pipeline projects, the contractor company was not expert on concreted steel-pipe assembly in flooded plots, what requires a different type of machinery. In this project, that was one of the bottlenecks.

Going to Gemba, the results were analysed in three criteria's: (a) type of construction operation under execution during the observation; (b) level of value-adding activity in each project; and (c) level of value-adding activity in each type of operation observed.

The consultants developed over 1090 observations in a total period of 72observation hours and more than 890 man hour considering the total of frontline workers on-site in each observation. Considering the critical path identified in the value stream mapping the main operations observed are shown in the Figure 1. Steel assembly, frames and concrete represent the highest amount of observation time (representing 67\% of the total time) it happened because, in seven of the nine projects, operations around steel-concrete structure were pointed as critical activities in the Value Stream Mapping even in Highway and Railway projects. On those projects (Highway and Railway, for example), bridges and viaducts were considered as critical activities for delivery time and costs, and, also, where were used the highest workforce level. In the second stage, with $21 \%$ of the observation time, is there earthworks, drainage, paving and excavation; operations clearly connected with heavy infrastructure constructions sites. 


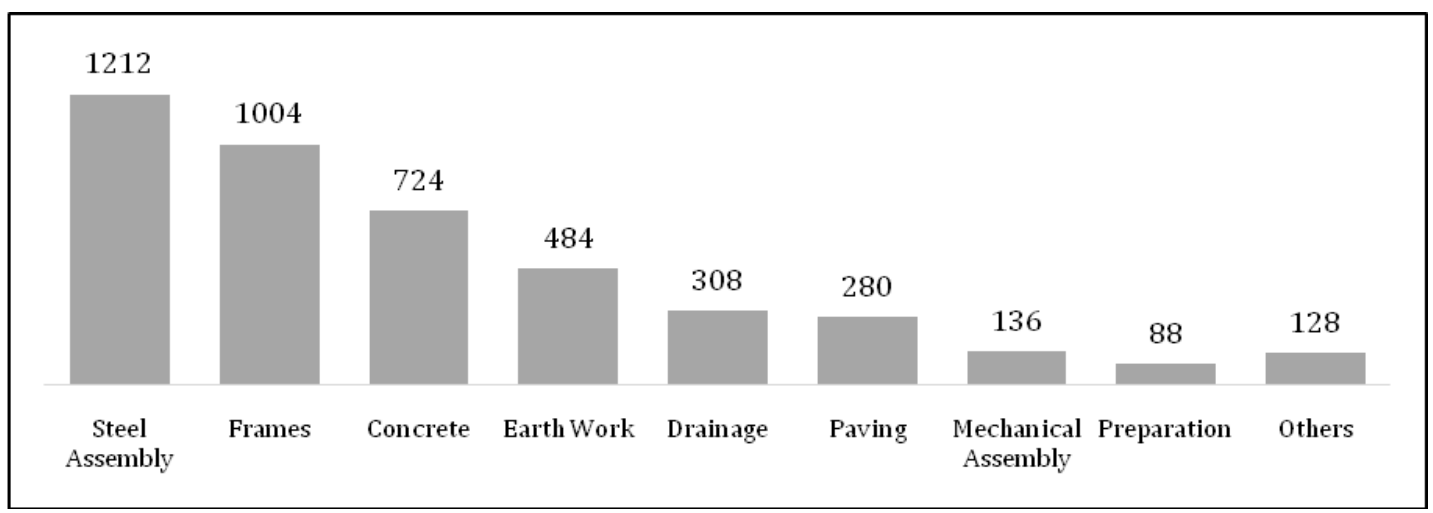

Figure 1: Time of analysis of each main activity on construction sites (time is represented in minutes)

The level of value-adding activities is shown in Figure 2. From top to bottom, it is shown, in top of the columns, the level of non-value activities and are not necessary for the construction process (wastes) like idleness, waiting, delays, defects and rework. In the middle, of Figure 2, it is represented in the middle of the columns, the non-value-adding activities but are necessary for the construction process like movements and motions. Thus, this slice of the production activities must be controlled and minimized. In the bottom are the value-adding activities and are the activities that really transform raw materials in final products and delivery value for the customer (final customer or intermediate customer). The results obtained in Gemba observation with the Multi Moment methodology, show the low level of value-adding activities in infrastructure construction project. The total observation time shows that only $26 \%$ of the workforce is operation on transformation. Only $17 \%$ of the time is spent in necessary non-valueadding activities. It is possible to see a very expressive level of non-value adding activities that are incorporated to those construction projects and in those Brazilian companies.

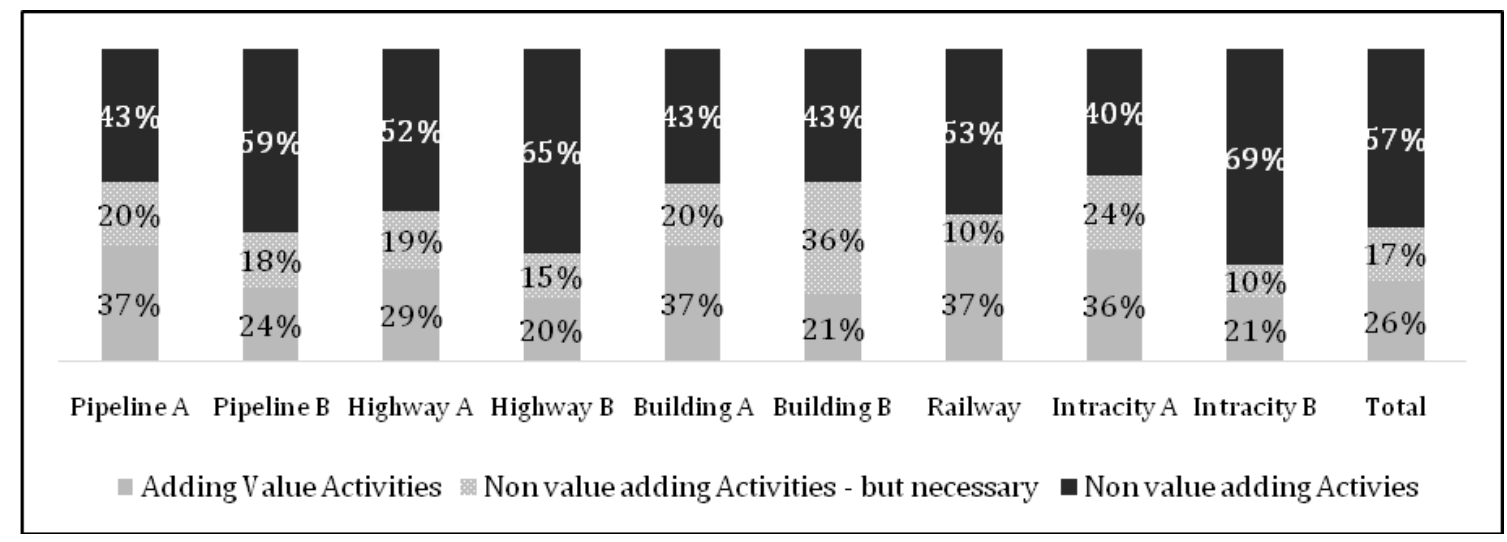

Figure 2: Value-adding activities level considering the projects observed 
Going deeper in the results analysis, the highest levels of non-value activities is observed in the Project Intracity B and Highway B (69\% and 65\% of non-value-adding activities), and that can be justified by the large dimensions and high volume of displacement and transportation, but the Highway A and Intracity A had a higher level of value-adding activities (29\% and $36 \%$ respectively) and have the same main characteristics. Is also interesting compare the results between Building A and Building B. In those projects the value-adding activities value varies in $76 \%$, from $37 \%$ in Building $\mathrm{A}$ to $21 \%$ in Building B. This focused analysis, comparing different projects but with similar product characteristics, bring the perspective of planning and preparation for the discussion. Poor work preparation and lack of a strong planning and control methodology is frequent in the nine observed projects.

Comparing the Intracity A and Intracity B. They were both developed in the same city, in the same period with same kind of workers, materials and weather. The technology and design were quite similar and we see a high difference of value-adding (Intracity A is $71 \%$ more productive than Intracity B). They had one great difference: were different construction companies, and different methodologies of contract managing, planning and controlling production and target deviation.

Finally, Figure 3 illustrates the analysis of the value stream critical operations. Thus, there is important to point that operations of paving and earth work had the lower level of value-adding activities, and it is so because of the high distances and necessity of movement, displacement and consequently of waiting (meanwhile a frontline worker transport some material or equipment, another frontline worker is waiting for the material or equipment). After, in the left side of Figure 3, it is represented the Steel Assembly as the third non-value-adding activities operation. Very frequently, Steel Assembly and Frames are operations of a high number of frontline workers involved. As higher the number of worker in an activity, higher is the waste level since the lack of production control is found. On the other hand, concrete operations are the highest level of valueadding activities since it is normally an activity that must be quick (considering the time the concrete can be managed), organized and requires a pre determinate number of frontline workers. On other hands, it is an activity that must have some planning and some level of preparation activities. 


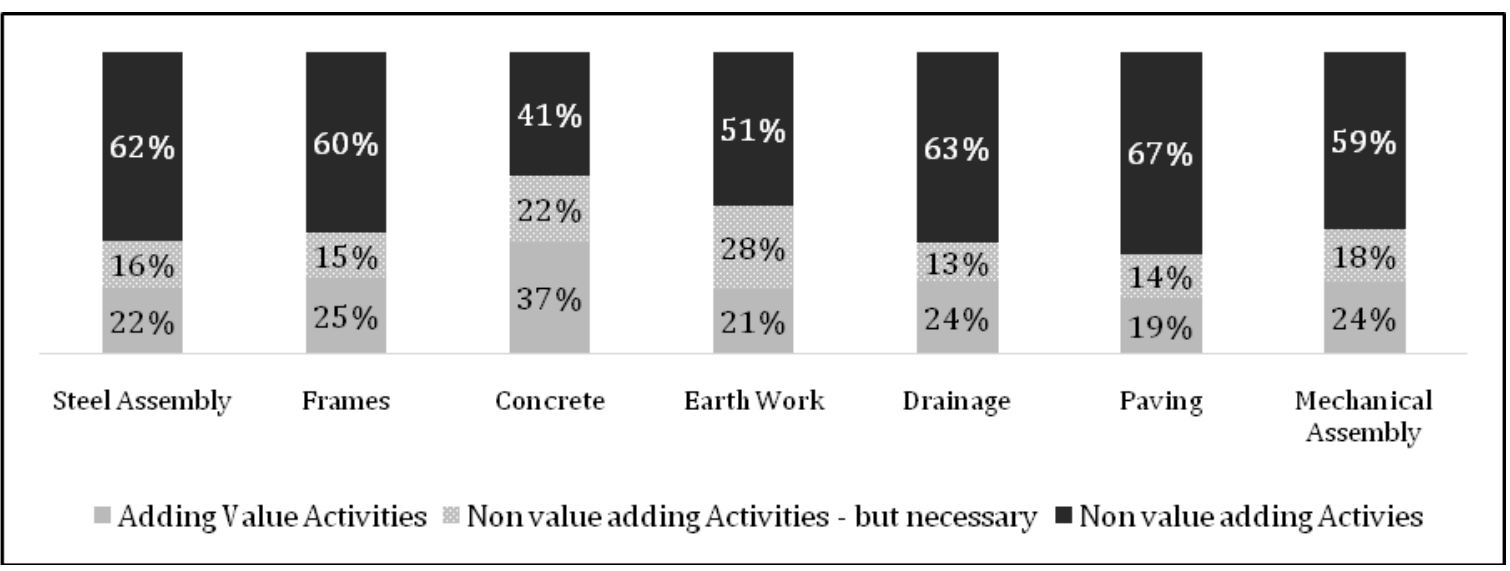

Figure 3: Value-adding activities level considering operations observed

\section{DISCUSSIONS AND CONCLUSIONS}

The papers objectives were achieved in analysing and quantifying the value-adding activities status in infrastructure projects in the public and private sector. The project also made use of production analysis tools that allowed the construction companies to understand their current status and the necessity of production improvement since the project understanding with the VSM, to the production wastes identification that occurred with the Gemba. The sample analysed enable to conclude that the MMA is an efficient tool to bring the understanding of value-adding activities in construction projects

The results show that $57 \%$ the construction activities observed did not add value $(69 \%$ and $65 \%$ on Intracity B and Highway B respectively). Being able to understand this level of waste, promote critical change actions is a fundamental stage in the performance improvement process, cost savings and a leaner construction management. The perception, identification and presentation of the level of wastes and non-value-adding activities to the Construction Companies managers brought a new managing attitude toward planning, control and understand their on-site activities, what is aligned with the conclusion from Shook (2009) and Kerem et al. (2013).

By implementing the described methodology even companies with high technical level and management team with extensive experience in infrastructure works, are unaware of a high level of non-value-adding activities. It is also clear to conclude that as more organized, prepared, planned, and controlled the activity is, better level of valueadding may be found (considering concrete works as a good example of preparation).

As suggestion for future work it is interesting to expand the number of projects analyzed, in different regions, in different branches of the construction, and with different kind of technologies in order to create a database that allows benchmarking, best practices and joint improvement of the sector.

The good news for the Brazilian scenario is that the perception for inefficiencies and the need for change exists and is perceived in the sector. Now it is time to seek for new alternatives to organize and improve production aiming to transform the construction in an even more competitive and efficient industry. 


\section{ACKNOWLEDGEMENTS}

We thank all the Construction Companies team involved in the projects and we are also grateful to Steinbock Consulting for the theoretical support and methodological tools used.

\section{REFERENCES}

Bulhões, I. R., Picchi, F. A., and Granja, A. D. (2011). "Combining Value Stream and Process Levels Analysis for Continuous Flow Implementation in Construction." 19th International Group for Lean Construction Conference: Proceedings, 99-107.

Covarrubias, A., Mourgues, C., and Arroyo, P. (2016). "VSM for Improving the Certificate of Occupancy Process in Real Estate Projects - A Chilean Case Study." In: Proc. 24rdAnn. Conf. of the Int'1. Group for Lean Construction, Boston, MA, USA,sect.4 pp. 123-132

Deschamps, R.R., Esteves, R.R., Rossetto, R., Tomazi, L.F. and Silva, G.G.M.P., 2015. "The impact of variability in workflow". In: Proceedings IGLC-23, Perth, Australia, July 29-31, pp. 826-835, available at www.iglc.net

Dos Reis, T. and Picchi, F.A. (2003). "Aplicaçãoda "Mentalidade Enxuta" ao Fluxo de Negócios na construção civil". Anais do III Simpósio Brasileiro de Gestão e Economia da Construção (Sibragec), UFSCar, São Carlos, SP, September 2013.

Fontanini, P. S. P., Picchi, F. A., Loureiro, S. A., and Lima Junior, O. F. (2008). "Simulation a construction supply chain - preliminary case study of pre-cast elements." IGLC 16 - International Group of Lean Construction, 371-380.

Issa, U.H., "Implementation of lean construction techniques for minimizing the risks effect on project construction time"; Civil Engineering Department, Faculty of Engineering, Minia University, Egypt; Alexandria Engineering Journal; August 2013, available at https://doi.org/10.1016/j.aej.2013.07.003

Kerem, C., Barak, R., Sacks, R., and Priven, V., "Learning to see - managers working in the gemba as part of the Tidhar waytraining program", Proceedings IGLC-21, July 2013, Fortaleza, Brazil

Koskela, L. (1992). "Application of the New Production Philosophy to Construction", Technical Report No. 72, CIFE, Stanford University, CA.

Koskela, L. (2000). "An Exploration towards a Production Theory and its Application to Construction”. PhD Diss., VTT Pub. 408, Espoo, Finland, 296 pp..

Koskela, L. ,Bølviken, T. \& Rooke, J. 2013, 'Which Are the Wastes of Construction?' In:,Formoso, C.T. \&Tzortzopoulos, P., 21th Annual Conference of the International Group for Lean Construction. Fortaleza, Brazil, 31-2 Aug 2013. pp 3-12

Ohno, T. (1988). "Toyota Production System; Beyond large scale production". Productivity Press, Portland, Oregon.

Plange, P. (2015). " Multi Moment Analysis - MMA: A new of way of getting information about your organization"; Nottwil, Switzerland

Picchi, F. A. (2003). "Oportunidades da aplicação do Lean Thinking na construção." Ambiente Construído, Porto Alegre, 3(1) 7-23, jan./mar. 
Pasqualini, F., and Zawislak, P. A. (2005). "Value Stream Mapping in Construction : a Case Study in a Brazilian Construction Company." 13th International Group for Lean Construction Conference., 117-125.

Rother, M. and Shook, J. (1998). "Aprendendo a enxergar: mapeando o fluxo de valor para agregar valor e eliminar o desperdício." Lean Institute Brasil.

Samudio, M., Thais da C.L. Alves, T. C. L. and Chambers, D.,"Employing the principle of "going and seeing" to construction", Proceeding IGLC 19 - Lima, Peru 2011

Shook, J. (2009). "How NUMMI Change Its Culture." Lean Enterprise Institute, Cambridge, MA

Shou, W., Wang, J., Chong, H.Y., and Wang, X. (2016). "Examining the Critical Success Factors in the Adoption of Value Stream Mapping." In: Proc. 24th Ann. Conf. of the Int'l. Group for Lean Construction, Boston, MA, USA, sect.1 pp. 93-102 